\title{
Physicochemical and Sensory Quality of Fermented Milk With Different Blends of Theobroma grandiflorum and Theobroma cacao
}

\author{
Nélio Ranieli F. Paula ${ }^{1}$, Érica O. Araújo ${ }^{1}$, Emily E. Almeida ${ }^{1}$ \& Aretha Steffany da Silva Rezende ${ }^{1}$ \\ ${ }^{1}$ Federal Institute of Education, Science and Technology, Rondonia State, Campus Colorado, Brazil \\ Correspondence: Érica O. Araújo, Federal Institute of Education, Science and Technology, Rondonia State, \\ Campus Colorado, Brazil. Tel: 69-98126-0921. E-mail: erica.araujo@ifro.edu.br
}

Received: December 16, 2019

Accepted: February 2, $2020 \quad$ Online Published: April 15, 2020

doi:10.5539/jas.v12n5p131

URL: https://doi.org/10.5539/jas.v12n5p131

\begin{abstract}
The production of fermented milk added of fruits is a considerable alternative for dairy industries and can constitute a rational and logical form of different types of processing, in various flavors, being part of a promising market in the Brazilian scenario. In view of the above, the present study aimed to research the biotechnological processes of production of fermented milk with different blends of cupuaçu (Theobroma grandiflorum) and cocoa (Theobroma cacao). The experimental design used was completely randomized, with six treatments, consisting of different concentrations of pulp (blends) of cocoa and cupuaçu (T1: 100\% cupuaçu, T2: $100 \%$ cocoa, T3: $50 \%$ cupuaçu $+50 \%$ cocoa, T4: $60 \%$ cupuaçu $+40 \%$ cocoa, T5: $70 \%$ cupuaçu $+30 \%$ cocoa, and T6: $80 \%$ cupuaçu $+20 \%$ cocoa) and four replicates. The results showed that the production of fermented milk added with $100 \%$ cocoa and $70 \%$ cupuaçu $+30 \%$ cocoa showed good lightness, yellowish color, slight sweetness and moderate acidity, according to the data of $\mathrm{a}^{*}, \mathrm{~b}^{*}, \%$ Brix and $\mathrm{pH}$. Fermented milk added of $100 \%$ cupuaçu, $70 \%$ cupuaçu $+30 \%$ cocoa and $60 \%$ cupuaçu $+40 \%$ cocoa had greater acceptability in regard to color and texture, while fermented milk added of $70 \%$ cupuaçu $+30 \%$ cocoa had the highest values of acceptability for aroma and flavor. The production of fermented milk with the use of different regional raw materials is feasible, because there is great potential as a sustainable alternative, and the addition of pulp of Amazonian fruits promotes greater nutritional and sensory value in fermented milk, contributing to the regional economy.
\end{abstract}

Keywords: Amazon, biotechnology, cupuaçu, cacao, fermentation, probiotic bactéria, production

\section{Introduction}

The Brazilian Amazon is rich in the diversity of plants that are still little explored by most of the population and that can become a food alternative of high nutritional value. Among the fruits of great importance for the Amazon region, cupuaçu (Theobroma grandiflorum) and cacao (Theobroma cacao) stand out as the most commercially exploited and are among the tropical fruits of excellent commercial value at the national and international levels. In the case of cupuaçu, the pulp is the most consumed part of the fruit and, due to the characteristics of acidity, pectin content, active aroma, pleasant flavor, richness in volatile compounds and mineral salts, it is an important raw material for the processing industry (Vriesman et al., 2009; Martins, 2008). Cocoa fruit contains substances with various functional properties, such as quercetin, rutin, ferulic, caffeic and coumaric acids (among others), catechins, methylxanthines (theophylline, theobromine, caffeine, etc.), various polyphenolic acids and flavonoids (Ferrari \& Torres, 2002), which are useful in the treatment of various pathologies.

The similarity between cupuaçu and cocoa seeds has aroused scientific interest, because chocolate-like products and chocolate drinks of excellent quality in terms of flavor can be obtained from fermented and toasted cupuaçu seeds. In this perspective, the use of pulp of Amazonian fruits or fermented seeds in formulations of fermented milk can give pleasant taste, improve nutritional value, and promote scientific and technological development. Milk has been constantly studied due to its nutritional profile, potential health benefits attributed to its consumption and the use of probiotic bacteria. In the latter case, the bacteria belonging to the genus Lactobacillus, such as the Lactobacillus casei, Lactobacillus casei shirota, Lactobacillus paracasei, Lactobacillus acidophilus and Lactobacillus zeae, are very often employed as probiotic supplements for food, especially for fermented milk (Alonso \& Isay, 2007). 
Fermented milks, according to the Technical Regulation of Identity and Quality of Fermented Milk (Brazil, 2007), are products added or not of other food substances obtained by coagulation and reduction in milk $\mathrm{pH}$, or reconstituted, added or not of other dairy products, by lactic fermentation through the action of cultures of specific microorganisms, and these must be viable, active and abundant in the final product during its shelf life (Brazil, 2007).

Thus, the production of fermented milk added of fruits is a considerable alternative for dairy industries and can constitute a rational and logical form of different types of processing, in various flavors, being part of a promising market in the Brazilian scenario. In addition, the potential of the Amazon region regarding the investment in food technology creates the opportunity for the discovery of new horizons for products with different treatments that meet the national and international consumer public, through the creation and exploitation of Amazonian products and species.

In view of the above, the present work aimed to research the biotechnological processes of production of fermented milk with different blends of cupuaçu (Theobroma grandiflorum) and cocoa (Theobroma cacao).

\section{Material and Methods}

The experiment was conducted at the premises of the Food Agroindustry of the Federal Institute of Education, Science and Technology of Rondonia, Colorado do Oeste Campus, in the municipality of Colorado do Oeste, RO, Brazil, at the geographic coordinates $13^{\circ} 06^{\prime} \mathrm{S}$ and $60^{\circ} 29^{\prime} \mathrm{W}$, with an average altitude of 407 meters.

The experimental design used was completely randomized, with six treatments, consisting of different concentrations of pulp (blends) of cacao and cupuaçu (T1: 100\% cupuaçu, T2: 100\% cacao, T3: $50 \%$ cupuaçu + 50\% cacao, T4: $60 \%$ cupuaçu $+40 \%$ cacao, T5: $70 \%$ cupuaçu $+30 \%$ cacao and T6: $80 \%$ cupuaçu $+20 \%$ cacao) and four replicates, totaling 24 experimental units.

The milk used to conduct the test was produced in the Animal Science sector of the Federal Institute of Education, Science and Technology of Rondonia, Colorado do Oeste Campus, and supplied to the Food Agroindustry. Initially, the milk was skimmed to have a maximum fat content of $0.5 \mathrm{~g} / 100 \mathrm{~g}$, according to the Normative Instruction $\mathrm{n}^{\circ} 62$ of 2011, in slow pasteurization, raising the temperature to $65^{\circ} \mathrm{C}$ for thirty minutes, followed by cooling to the incubation temperature of the fermenting microorganisms at $37{ }^{\circ} \mathrm{C}$ (Lactobacillus casei shirota), in a rigorously controlled environment for a period of 7 hours. Milk fermentation occurred until the $\mathrm{pH}$ of the medium reached values of $4.0( \pm 0.25)$. This $\mathrm{pH}$ interval was determined considering the sensory and conservation characteristics of the product.

The production of fermented milk in the presence of the different blends of cocoa and cupuaçu was performed by adding concentrations of cocoa pulp and concentrations of cupuaçu pulp, considering the aforementioned treatments. After milk pasteurization, syrup was prepared and added, part of it constituted by $10 \%$ sugar, in each sample, respecting the equivalent concentrations of pulp for each treatment (blends of cupuaçu and cocoa).

Treatments that, after processing, showed apparent viscosity visually similar to/compatible with that of fermented milk existing on the market were subjected to physicochemical analyses: $\mathrm{pH}$, acidity, colorimetric parameters $\mathrm{L}^{*}$ (lightness ranging from 0 [totally black] to 100 [totally white], $\mathrm{a}^{*}\left(-80\right.$ green to +100 red) and $\mathrm{b}^{*}$ (intensity from -50 blue to +70 yellow), and ${ }^{\circ}$ Brix.

The sensory acceptance test (attributes: color, texture, consistency, aroma, flavor and overall aspect) was conducted at seven days of storage. Sensory evaluation of acceptance was performed by untrained tasters (40 tasters) and considering the scores according to the hedonic scale with values from 1 to 9 points (1-disliked extremely, 2-disliked very much, 3-disliked moderately, 4-disliked slightly, 5-Neither liked nor disliked, 6-liked slightly, 7-liked moderately, 8-liked very much and 9-liked extremely), indicating how much they liked or disliked the color, texture, aroma, flavor and overall aspect of products.

Physicochemical and sensory results were subjected to analysis of variance and the differences between means were compared by Tukey test at 5\% significance level, using Sisvar software.

\section{Results and Discussion}

The results showed significant effects $(\mathrm{p} \leq 0.05)$ of the treatments composed of different concentrations of cacao and cupuaçu pulp on the parameters $\mathrm{L}^{*}, \mathrm{a}^{*}, \mathrm{~b}^{*},{ }^{\circ} \mathrm{Brix}, \mathrm{pH}$ and sensory analysis (Tables 1 and 2 ). 
Table 1. Summary of analysis of variance for $\mathrm{L}^{*}, \mathrm{a}^{*}, \mathrm{~b}^{*}$, ${ }^{\circ}$ Brix, acidity and $\mathrm{pH}$ of fermented milk with different concentrations of cupuaçu and cacao pulp. Colorado do Oeste, RO, Brazil (2019)

\begin{tabular}{llllllll}
\hline Source of variation & GL & $\mathrm{L}^{*}$ & $\mathrm{a}^{*}$ & $\mathrm{~b}^{*}$ & ${ }^{\circ}$ Brix & Acidity & $\mathrm{pH}$ \\
\hline Treatment & 5 & $0.00^{*}$ & $0.00^{*}$ & $0.00^{*}$ & $0.00^{*}$ & 0.09 & $0.00^{*}$ \\
Repetition & 3 & 0.16 & 0.22 & 0.99 & 0.67 & 0.44 & 0.39 \\
Residue & 15 & & & & & & \\
\hdashline Average & & 57.45 & 5.45 & 4.88 & 18.08 & 121 & 4.95 \\
CV $(\%)$ & 4.33 & 14.56 & 10.39 & 1.27 & 15.86 & 1.57 \\
\hline
\end{tabular}

Note. $*$ Significant at $5 \%$ probability by Tukey test.

Table 2. Summary of analysis of variance for sensory analysis (color, texture, consistency, aroma, flavor and aspect) of fermented milk with different concentrations of cupuaçu and cacao pulp. Colorado do Oeste, RO, Brazil (2019)

\begin{tabular}{llllllll}
\hline Source of variation & GL & Color & Texture & Consistency & Aroma & Flavor & Aspect \\
\hline Treatment & 5 & $0.00^{*}$ & $0.00^{*}$ & 0.09 & $0.00^{*}$ & $0.00^{*}$ & $0.00^{*}$ \\
Repetition & 3 & 0.82 & 0.41 & 0.82 & 0.71 & 0.66 & 0.00 \\
Residue & 15 & & & & & & \\
\hdashline Average & & 7.61 & 7.77 & 8.05 & 8.05 & 7.70 & 7.83 \\
CV $(\%)$ & 4.66 & 2.47 & 4.56 & 3.54 & 1.56 & 1.67 \\
\hline
\end{tabular}

Note. * significant at $5 \%$ probability by Tukey test.

The colorimetric parameter $\mathrm{L}^{*}$ was higher in the treatment with $100 \%$ cupuaçu, statistically differing from the others $(\mathrm{p}<0.05)$, which enables the inference that the treatment promoted greater lightness in the product, but it did not corroborate the data of $\mathrm{a}^{*}$ and $\mathrm{b}^{*}$ (Figure 1).

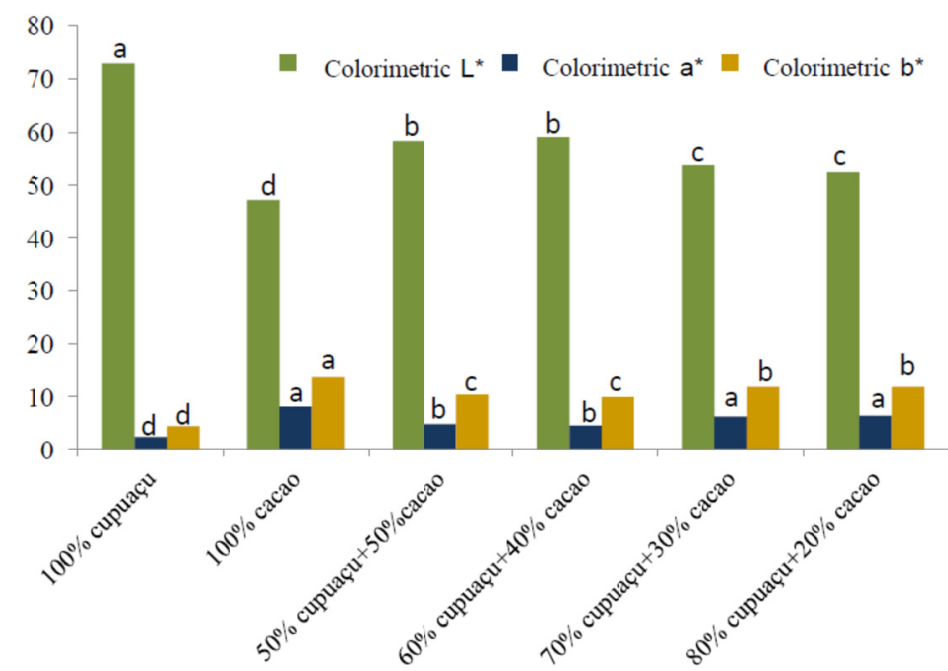

Figure 1. Colorimetric parameters $L^{*}, a^{*}$ and $b^{*}$ of fermented milk with different concentrations of cupuaçu and cacao pulp. Lowercase letters separate the means within each bar and equal letters do not differ by

Tukey test at $5 \%$ probability level

Regarding the colorimetric parameters $\mathrm{a}^{*}$ and $\mathrm{b}^{*}$, the treatment with $100 \%$ cocoa had significantly higher values than the others (Table 1) and consequently higher values of ${ }^{\circ}$ Brix (Figure 2A) and lower values of pH (Figure 2B). These data reveal good lightness, yellowish color, slight sweetness and moderate acidity for fermented milk added with $100 \%$ cacao pulp. It is important to point out that the treatment with concentration of $100 \%$ cacao did not differ statistically from the treatment with $70 \%$ cupuaçu $+30 \%$ cacao for $\%$ Brix (Figure $2 \mathrm{~A}$ ), so it is possible to affirm that cupuaçu contributed to reducing $\mathrm{pH}$ values and increasing the acidity of fermented milk. It can be observed that the obtained values of $a^{*}$ (red/green intensity) are closer to light green and the values of $b^{*}$ 
(yellow/blue intensity) indicated intensity for dark, slightly brown yellow. In this context, the results showed an inverse relationship regarding the addition and mixture of different concentrations of cacao and cupuaçu. Thus, the lower the values of $\mathrm{a}^{*}$, the higher the lightness $\left(\mathrm{L}^{*}\right)$ of the blends formulated; consequently, the higher the values of $* b$, the lower the lightness $\left(\mathrm{L}^{*}\right)$ of the treatments studied.

The ${ }^{\circ}$ Brix scale is calibrated by the number of grams of sugar contained in $100 \mathrm{~g}$ of solution. When the refractive index of a sugar solution is used, the reading as ${ }^{\circ}$ Brix percentage should match the actual sugar concentration in the solution. Scales in ${ }^{\circ}$ Brix percentage present the percentage concentrations of the soluble solids contained in a sample (solution with water). The soluble solids contained is the total of all solids dissolved in water, starting with sugar, salts, proteins, acids, etc. Higher values of \%Brix and lower values of $\mathrm{pH}$ were observed in the respective blends ( $70 \%$ cupuaçu $+30 \%$ cacao and $80 \%$ cupuaçu $+20 \%$ cacao) (Figure $2 \mathrm{~A}$ ), so the product complies with the Technical Regulation of Identity and Quality, which establishes pH between 2.70 and 3.80 , minimum acidity of $2.50 \%$ of citric acid and at least $11^{\circ}$ Brix (Brazil, 2000).

The reading of the measured value is the total sum of these values. The analysis of the amount of Total Soluble Solids (TSS) through refractometry on the Brix scale constitutes a method accepted by the academic community. Thus, the mean TSS content in the analyzed products ranged from 16.95 to 19.05 for the different treatments of fermented milk with different concentrations of cupuaçu and cacao pulp (Figure 2A).
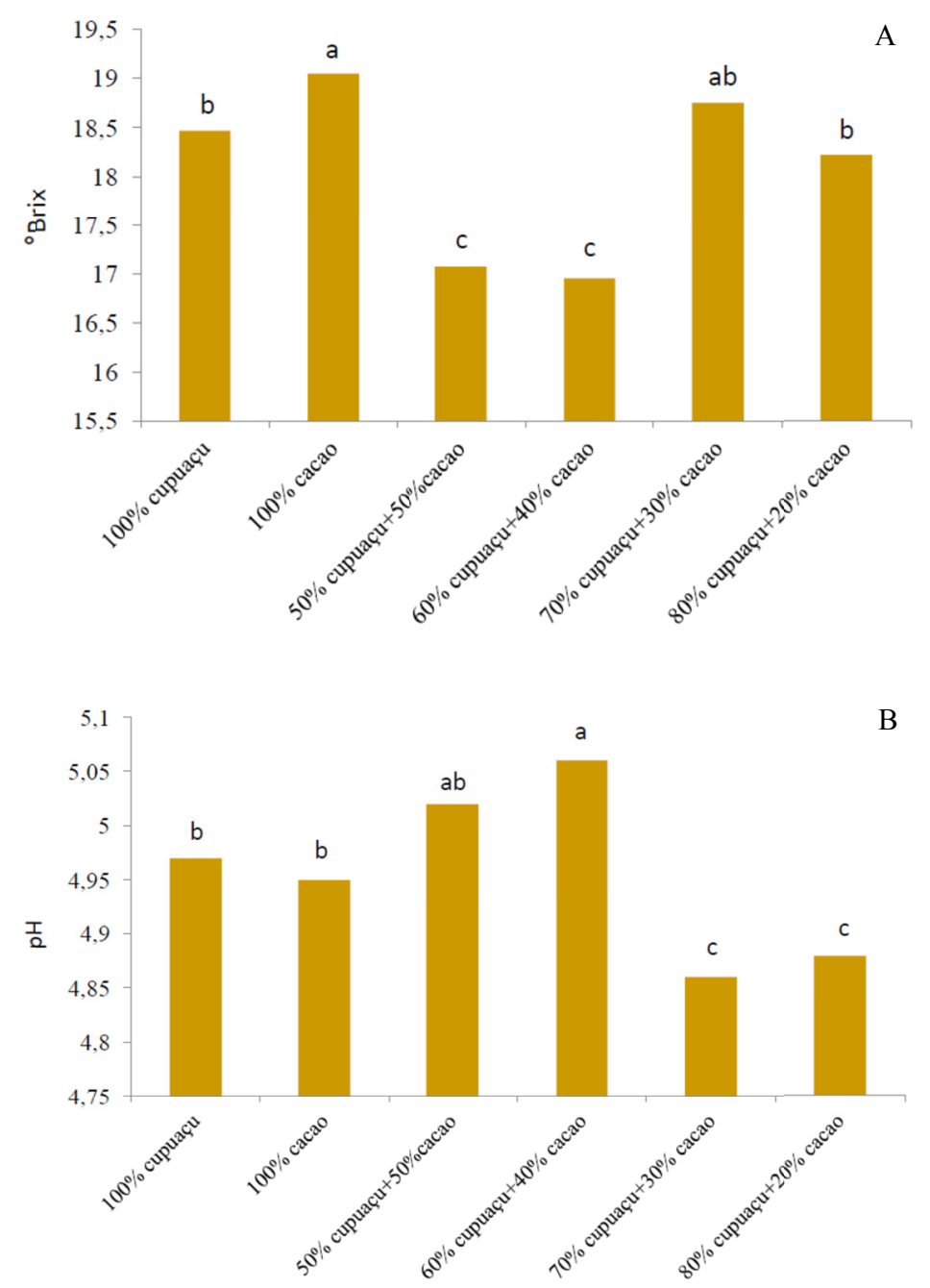

Figure 2. ${ }^{\circ}$ Brix (A) and $\mathrm{pH}(\mathrm{B})$ of fermented milk with different concentrations of cupuaçu and cacao pulp. Lowercase letters separate the means within each bar and equal letters do not differ by Tukey test at 5\% probability level 
According to the obtained data, the $\mathrm{pH}$ values observed in the different treatments meet the minimum value established for fermented milk recommended by the Technical Regulation of Identity and Quality (RTIQ) of Fermented Milk (Brazil, 2007) (Figure 2B). Although there was no significance $(p>0.05)$ for acidity in the different blends of fermented milk with cupuaçu and cacao, all treatments showed high values of final acidity, which confirms the correct completion of the fermentation process of the products, determined using the percentage of lactic acid as a parameter, since the value should be at least $0.60 \%$ to inhibit the growth of pathogenic or deteriorating bacteria that may be present in the product (Brazil, 2000). According to the results, a positive, direct and significant relationship was observed with respect to the cupuaçu contents added in the developed blends (Figure 2B).

The most accepted treatments with different concentrations of cupuaçu and cacao pulp in relation to the attributes of color and texture, considering the average values close to the descriptive terms "liked slightly" and "liked moderately", were those with $100 \%$ cupuaçu, $70 \%$ cupuaçu $+30 \%$ cacao and $60 \%$ cupuaçu $+40 \%$ cacao, which led to the highest values of acceptability for all attributes mentioned above and did not differ statistically from one another (Figure 3A). It is important to highlight that color is the first criterion evaluated by the consumer in the acceptance or rejection of a product, that is why color is an attribute in the food industry because, for the consumer, if the color is attractive, the food will likely be ingested or at least tasted. The data found in sensory analysis for the color attribute corroborate those of the colorimetric parameter $\mathrm{L}^{*}$.

Regarding aroma, the treatments with $100 \%$ cupuaçu and $100 \%$ cacao had the lowest values of acceptability, while the treatment with $70 \%$ cupuaçu $+30 \%$ cacao showed the highest values of acceptability for both aroma and flavor, with average values on the order of 9 (liked extremely) according to the hedonic scale (Figure 3B), which indicates that these products have good acceptance and can be marketed. According to Dutcosky (2011), the product reaching a percentage equal to or greater than $70 \%$ is considered accepted by the tasters. There was statistical difference in the overall aspect of the products only for the treatment with $100 \%$ cacao, which differed statistically from the others $(\mathrm{p}<0.05)$ (Figure 3C).

However, the development and evaluation of fermented milk with different concentrations of cupuaçu and cacao pulp shows great social importance, diversification of production, improvements in the development of regional products and guarantee of food and nutritional safety for society, due to the use of technologies and selection of raw material, through the application of good manufacturing practices, respecting the standards of quality and hygiene.

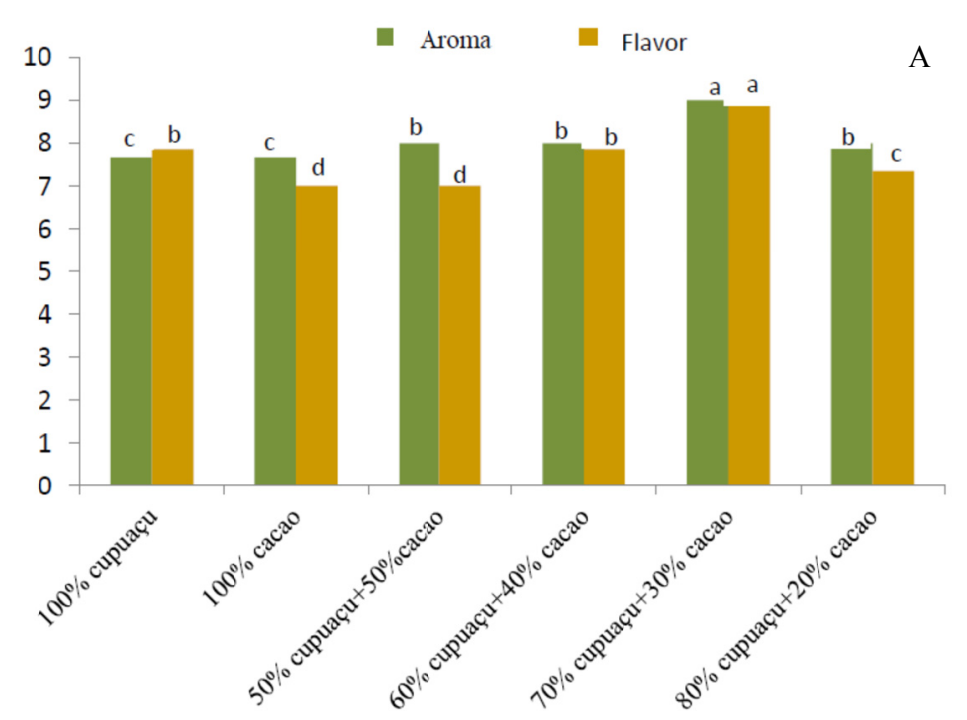



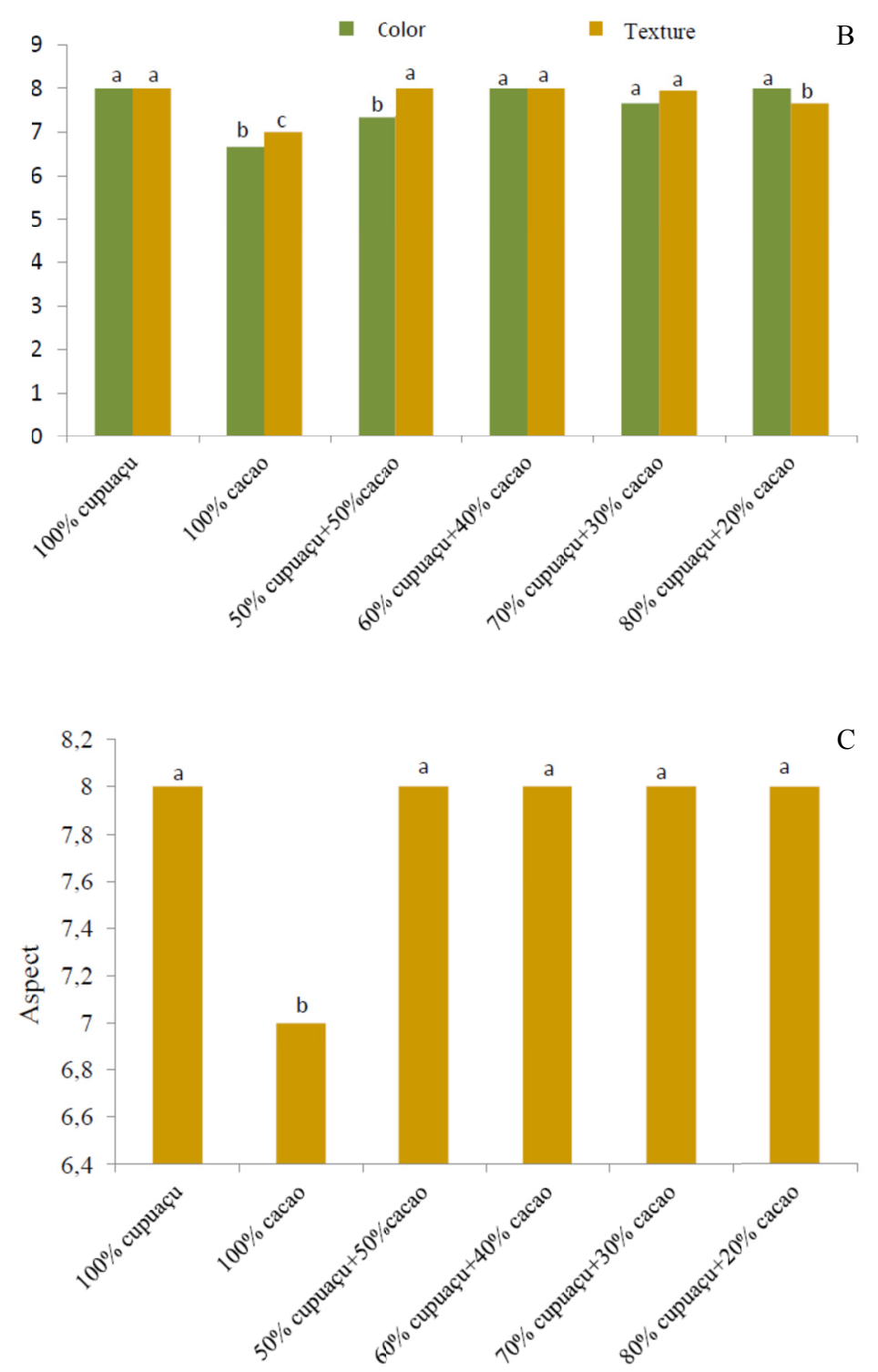

Figure 3. Sensory analysis of fermented milk with different concentrations of cupuaçu and cacao pulp. Color and Texture (A), Aroma and flavor (B) and aspect (C). Lowercase letters separate the means within each bar and equal letters do not differ by Tukey test at $5 \%$ probability level. $n=40$ judges. Structured hedonic scale of nine points $(1=$ disliked extremely; $9=$ liked extremely $)$. Values correspond to the mean with estimate of the standard deviation

In all treatments of the fermented milk developed (blends of cacao + cupuaçu, pure cacao and pure cupuaçu), the Most Probable Numbers $/ \mathrm{mL}\left(\mathrm{MPN} / \mathrm{mL}\right.$ ) of coliforms at $35{ }^{\circ} \mathrm{C}$ and coliforms at $45{ }^{\circ} \mathrm{C}$ were lower than 0.1 MPN $/ \mathrm{mL}$. According to the RTIQ of Fermented Milk (Brazil, 2005), the MPN $/ \mathrm{mL}$ of coliforms allowed for fermented dairy beverages are up to $100 \mathrm{MPN} / \mathrm{mL}$ of coliforms at $35^{\circ} \mathrm{C}$ and $10 \mathrm{MPN} / \mathrm{mL}$ of coliforms at $45{ }^{\circ} \mathrm{C}$ for indicative samples. The results indicate adequate hygienic-sanitary quality throughout the process of production and storage of fermented milk and demonstrate microbiological quality above the level required by the current legislation, hence suitable for consumption (Table 3). In the Brazilian legislation, Salmonella spp. must be completely absent (Brazil, 2001). The shelf life of fermented milk was longer than 60 days, with the maintenance of quality of the sensory characteristics of the product. 
Table 3. Microbiological analysis of total coliforms (TC), thermotolerant coliforms (TTC) at $45^{\circ} \mathrm{C}$, Escherichia coli, Staphylococcus aureus and Salmonella sp. in fermented milk with different concentrations of cupuaçu and cacao blends. Colorado do Oeste, RO, Brazil (2019)

\begin{tabular}{llllll}
\hline Treatment & $(\mathrm{TC})$ & $(\mathrm{TTC})$ & Escherichia coli & Estafilococos aureus & Salmonella sp. \\
\hline $100 \%$ cupuaçu & $\leq 0.1$ & $\leq 0.1$ & Absence & Absence & Absence \\
$100 \%$ cacao & $\leq 0.1$ & $\leq 0.1$ & Absence & Absence & Absence \\
$50 \%$ cupuaçu+50\%cacao & $\leq 0.1$ & $\leq 0.1$ & Absence & Absence & Absence \\
$60 \%$ cupuaçu $+40 \%$ cacao & $\leq 0.1$ & $\leq 0.1$ & Absence & Absence & Absence \\
$70 \%$ cupuaçu+30\%cacao & $\leq 0.1$ & $\leq 0.1$ & Absence & Absence & Absence \\
$80 \%$ cupuaçu+20\%cacao & $\leq 0.1$ & $\leq 0.1$ & Absence & Absence & Absence \\
\hline
\end{tabular}

Note. The values correspond to the average of four repetitions. *Reference standards according to Normative Instruction $\mathrm{N}^{\mathrm{o}}$. 16 of 08/23/2005 of the Ministry of Livestock Agriculture and Supply.

\section{Conclusions}

Fermented milk added of concentrations of $100 \%$ cacao and $70 \%$ cupuaçu $+30 \%$ cacao showed good lightness, yellowish color, slight sweetness and moderate acidity, according to the data of $\mathrm{a}^{*}, \mathrm{~b}^{*}, \% \mathrm{Brix}$ and $\mathrm{pH}$.

Fermented milk with $100 \%$ cupuaçu, $70 \%$ cupuaçu $+30 \%$ cacao and $60 \%$ cupuaçu $+40 \%$ cacao had greater acceptability in terms of color and texture, while fermented milk with $70 \%$ cupuaçu $+30 \%$ cacao showed the highest values of acceptability for aroma and flavor.

The production of fermented milk with the use of different regional raw materials is feasible, as there is great potential as a sustainable alternative, and the addition of pulp of Amazonian fruits promotes greater nutritional and sensory value in the fermented milk, contributing to the regional economy.

\section{References}

Alonso, B. F. C., \& Isay, S. S. M. (2007). Bacteria of the Lactobacillus casei group: characterization, feasibility as probiotics in food and their importance for human health. Organo Oficial de la Sociedad Latinoamericana de Nutrición, 57(4), 373-380.

Brazil, Ministry of Agriculture, Livestock and Supply. (2003). Secretariat of Animal Product Inspection. Normative Instruction No. 62 of August 26, 2003 (Section 1, p. 14). It formalizes official analytical methods for microbiological analysis for the control of products of animal origin and water. Official Gazette [of] Federative Republic of Brazil, Brasília, DF.

Brazil, Ministry of Agriculture, Livestock and Supply. (2005). Secretariat of Animal Product Inspection. Normative Instruction No. 16 of August 23, 2005 (Section 1, p. 7). Approves the Technical Regulation of Identity and Quality of Milky Beverages. Official Gazette [of] Federative Republic of Brazil, Brasília, DF.

Brazil, Ministry of Agriculture, Livestock and Supply. (2007). Secretariat of Animal Product Inspection. Normative Instruction No. 46 of October 23, 2007 (Section 1, p. 5). It adopts the Technical Regulation of Identity and Quality of Fermented Milks. Official Gazette [of] Federative Republic of Brazil, Brasília, DF.

Dutcosky, S. D. (2011). Sensory analysis of food (3rd ed., p. 426). Curitiba: Editora Champagnat.

Ferrari, C. K. B., \& Torres, E. A. F. S. (2002). Functional foods: When good nutrition improves our health. Revista Portuguesa Saúde Publica, 20(1), 31-34.

Lopes, A. S., García, N. H. P., \& Vasconcelos, M. A. M. (2003). Evaluation of roasting conditions after fermentation of cupuaçu almonds (Theobroma grandiflorum Schum) and cocoa (Theobroma cacao). Brazilian Journal of Food Technology, 6(2), 309-316.

Martins, V. B. (2008). Sensory profile of tropical cupuaçu juice (Theobroma grandiflorum Schum) (p. 366, Thesis (Doctorate in Food and Nutrition), State University of Campinas, SP).

Vriesman, L. C., Silveira, J. L. M., Carmen, L. D. O., \& Petkowicz, C. L. O. (2009). Chemical and rheological properties of a starch rich fraction from the pulpo fthe fruit cupuassu (Theobroma grandiflorum). Brazil Materials Science and Engineering, 29, 651-656. https://doi.org/10.1016/j.msec.2008.12.011 


\section{Copyrights}

Copyright for this article is retained by the author(s), with first publication rights granted to the journal.

This is an open-access article distributed under the terms and conditions of the Creative Commons Attribution license (http://creativecommons.org/licenses/by/4.0/). 